\title{
HOW TO: Record fires that burned thousands of years ago
}

Emma Rehn

Fire has shaped environments around the world over thousands of years, sometimes controlled by people or by changing climates - but how do we know what fires were like in the past? Scientists use a range of methods to learn more about past fires, including how often fires happened and what types of plants were burning. This graphic briefly shows how these methods have been used to look at fires in northern Australia, and why looking at thousands of years of fires can help us understand and make decisions about fires today.

\section{Fires today}

Fire plays a key role in environments around the world, but climate change is causing large, destructive fires to happen more often in many places. In southeast Australia in 2019-2020, intense bushfires destroyed more than 3000 houses and burned across an area bigger than the size of England (DPS March 2020). But written records of fires in Australia only go back around 100 years - we need to know if times of fires like this have happened before, what fires were like when things like long droughts happened in the past, and how cultural burning by people might keep fires smaller and less intense.

This is where lake mud can help. Fires burn plants into things like charcoal and ash. This charcoal can fall or be washed by rain into lakes and settle at the bottom, building up in layers of mud. Scientists can use this mud to make records of fires far into the past.

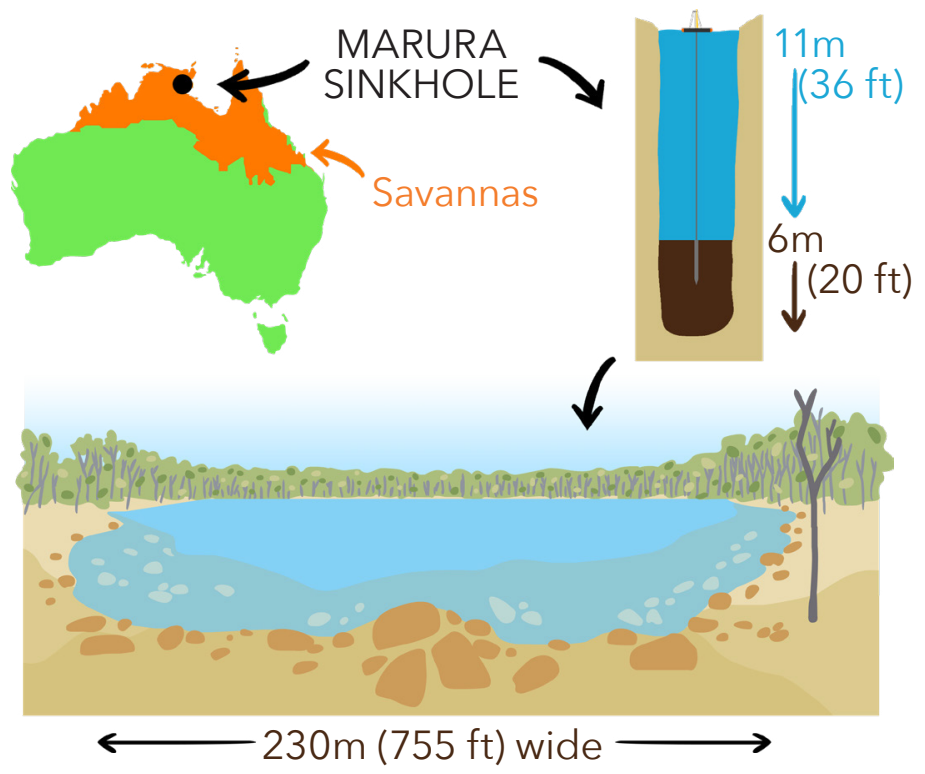

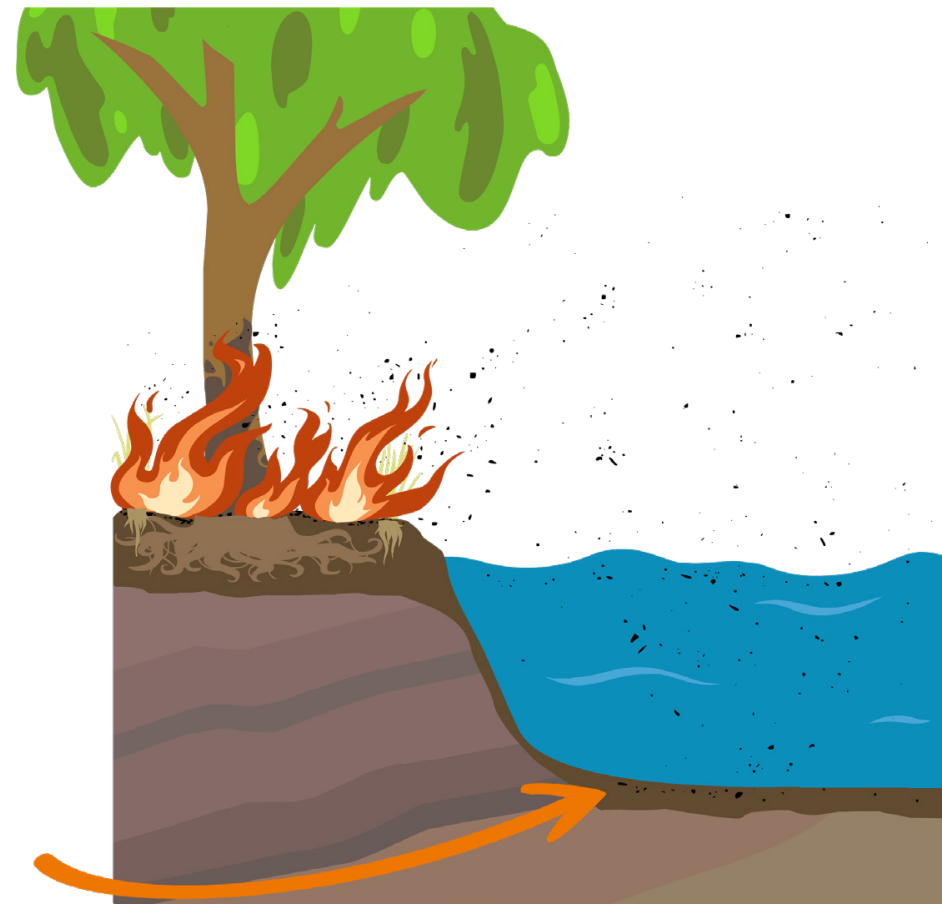

We can see how this works at Marura sinkhole in northern Australia. Marura ("Mah-ROO-rah") is 11 meters (36 ft) deep, with 6 meters ( $20 \mathrm{ft}$ ) of mud at the bottom that has built up over 10,000 years. The savanna (a mix of grasses and trees) around Marura sometimes burns every year. The Indigenous people of the land, the Yolngu, still live in the area but many were moved away or killed when Europeans colonized Australia.

Recording the history of ancient bushfires at Marura will show how cultural burning by Indigenous people affected fire, and how fires have changed recently.

We collected samples (sediment cores) from Marura and applied different methods to see what fire was like there over the last 4,600 years.

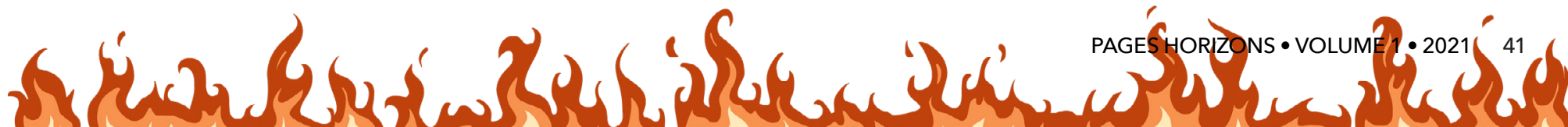




\section{How much fire was there?}

Key areas for reconstructing past fires include fire abundance (how much), fire incidence (when), and fire frequency (how often). The two broad approaches to this are OPTICAL and CHEMICAL:

\section{OPTICAL: CHARCOAL}
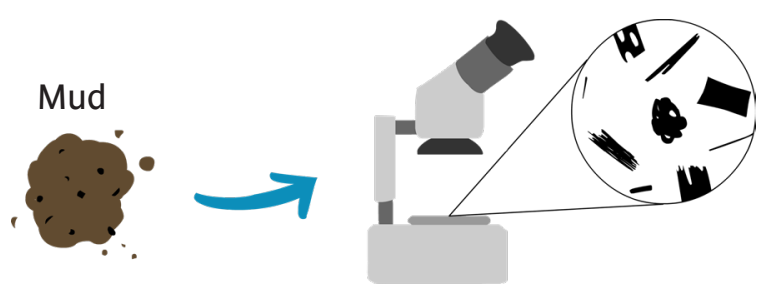

Charcoal particles on slides or in a petri dish in water can be put under a microscope for counting by an analyst. Larger charcoal often represents fires close by, while smaller particles are created in both nearby and distant fires. Samples can also be processed, using a combination of chemicals, heat, and pressure, to separate out carbon burned by fires (black carbon).

\section{CHEMICAL: BLACK CARBON}
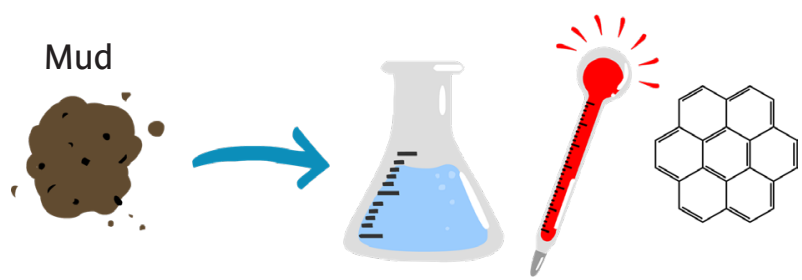

Chemical methods isolate the most resistant black carbon (made under higher fire intensities and temperatures) but optical counting includes charcoal made under all temperatures, so these techniques can be combined to look at fire intensity. This is important because cultural burning usually creates cool, low-intensity fires.

\section{What was burning?}

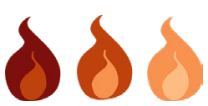

It is important to know when fires happened but also what plants were burning. Plants and fire influence each other, with some fuel types encouraging fire and some fire regimes leading to more grasses versus trees. There are optical and chemical methods to look at what was burning:

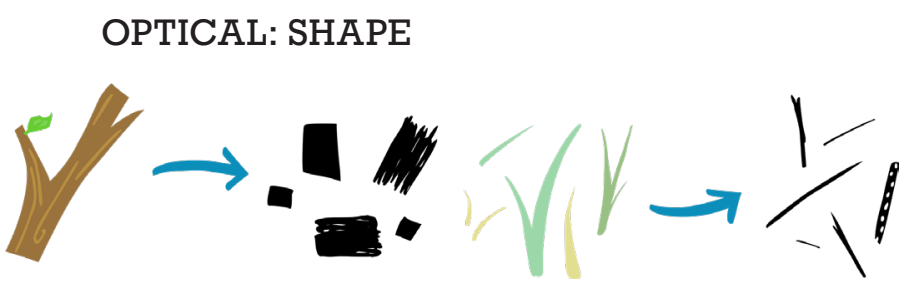

The shape of a charcoal particle can reflect what type of plants burned to create it. Grasses and sedges when burned create long, skinny charcoal particles while wood charcoal is blocky, so recording charcoal shapes shows how much grasses versus trees were burning. Some plants can also be identified chemically using isotopes of carbon (an isotope is an atom with different numbers of neutrons). In northern Australia, most trees are $C_{3}$ types with a lower $\delta^{13} \mathrm{C}$ ("delta-C-13") number and grasses are $\mathrm{C}_{4}$ types with a higher number.
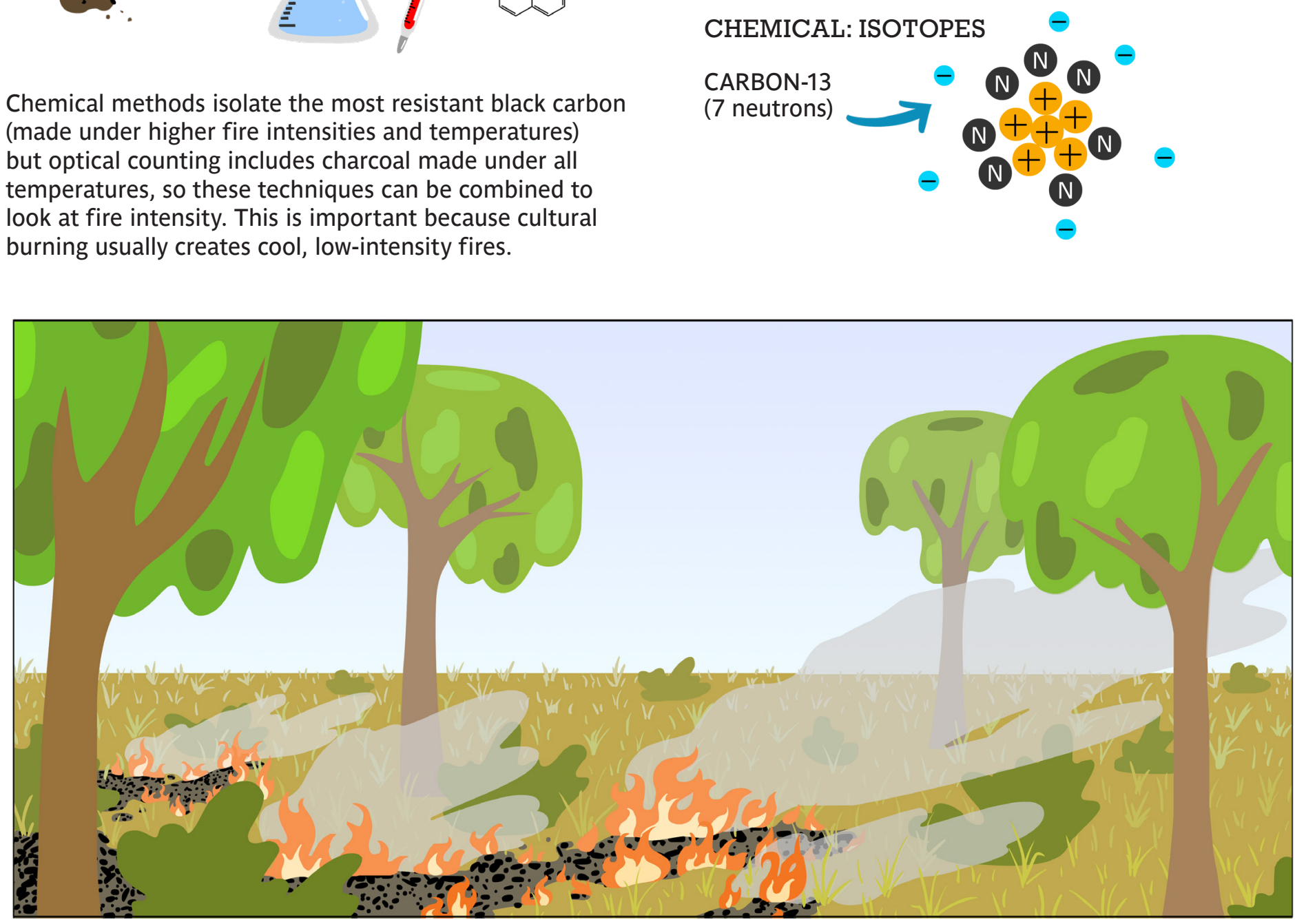


\section{Putting it together at Marura}

The Marura record shows that a lot of plant material was burning over 4000 years ago and has declined since then. Fires around Marura have been a mix of different intensities, with high-intensity fires happening regularly from about 4600-2600 years ago and less often after that, probably because of Indigenous cultural burning creating more low-intensity fires. Recent burning has been high intensity.

\section{Vegetation}

The mix of grass and trees around Marura hasn't changed too much, and only a few hot fires early in the record show any effect on plants (those fires burned mostly trees and shrubs). The record of fire at Marura shows that much more was burning 4000 years ago than today. High intensity fires happened about every 400 years until around 2600 years ago, when we know that Indigenous people were living on the nearby coast, and cultural burning kept fire intensities lower. Higher fire intensity in the recent past shows that fires may be increasing in amount and intensity in a way that hasn't happened at Marura in the last 900 years.

The Marura fire record shows how to look at bushfires thousands of years in the past, and will hopefully help land managers make decisions about fire in the future. As scientists improve these methods, create new techniques, and study more sites around the world, we get a better picture of what fire was like in the past to better plan for the future. (5)
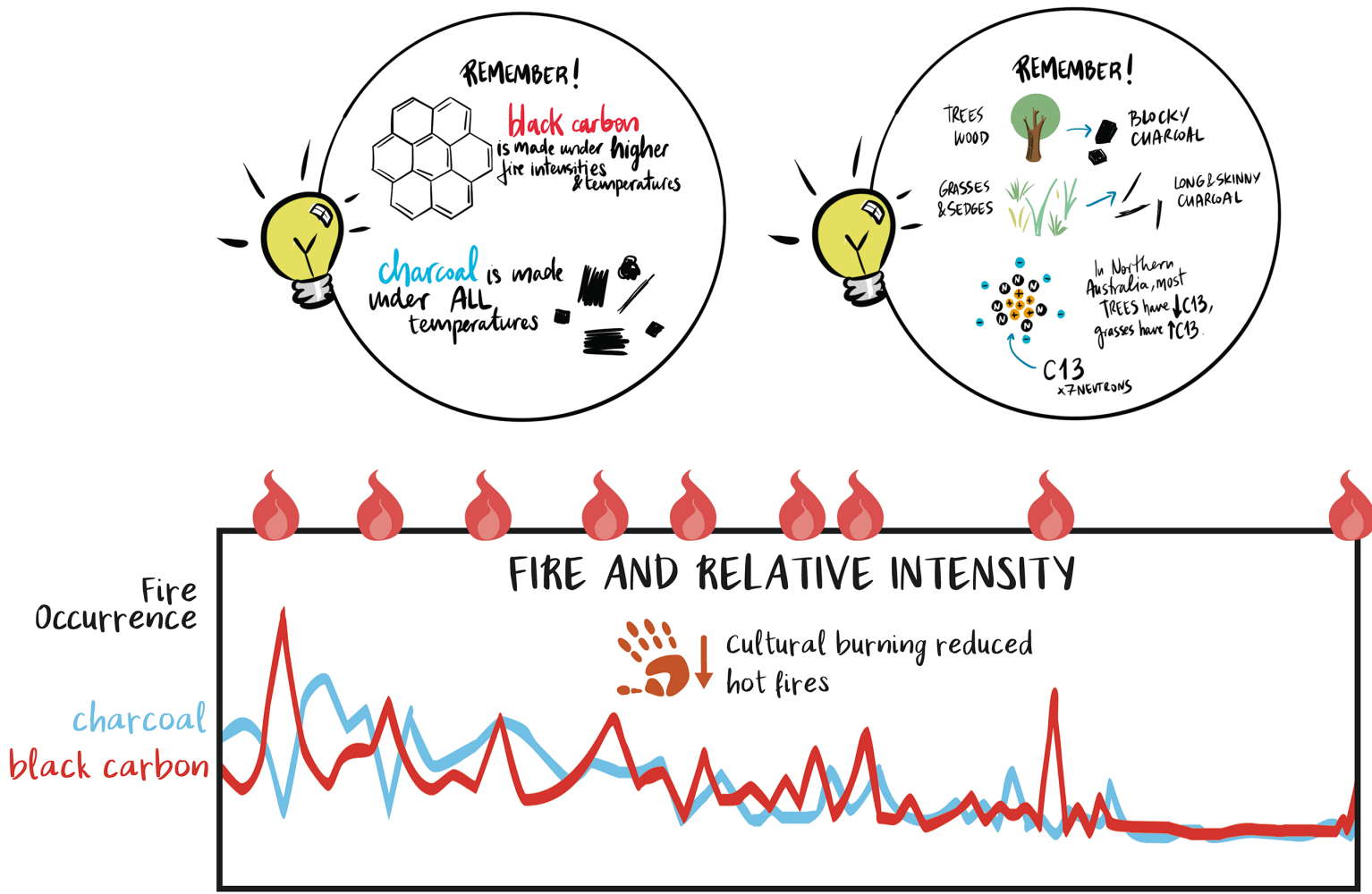

Intense

Fire Events

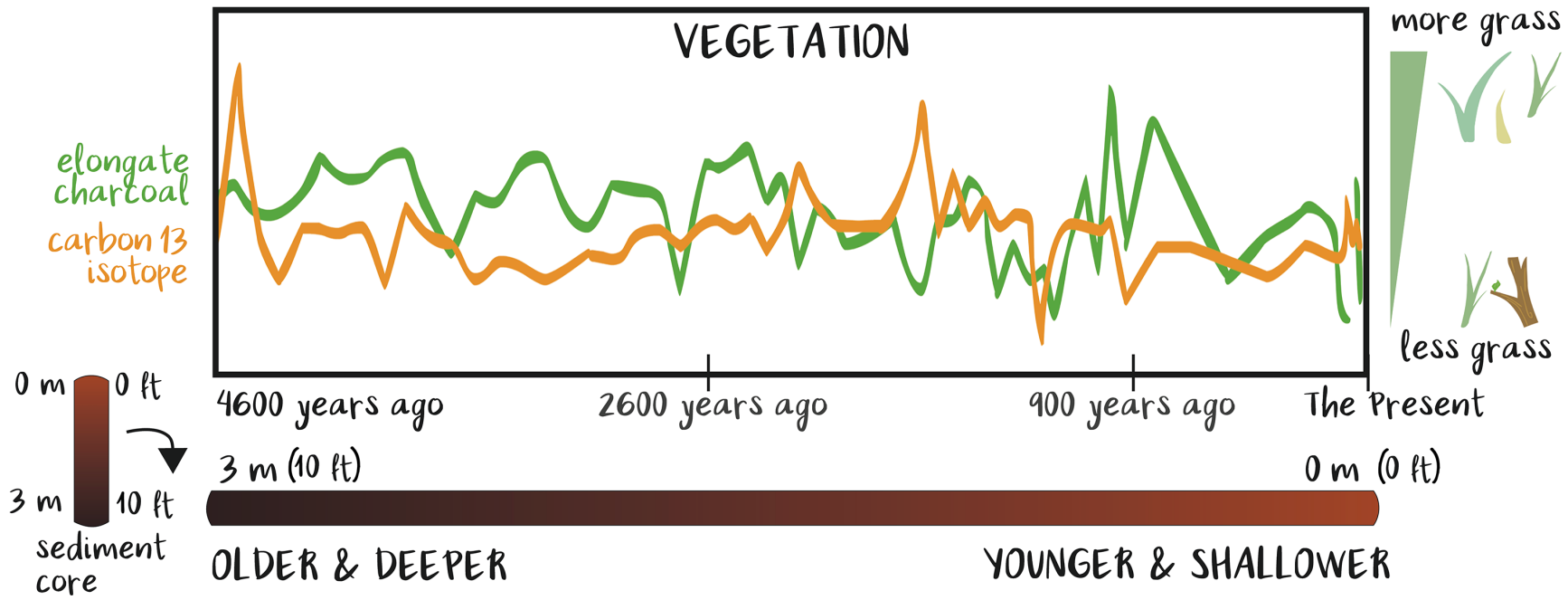

